\title{
First results of low frequency electromagnetic wave detector of TC-2/Double Star program
}

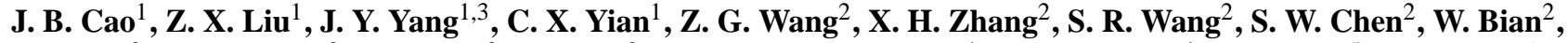 \\ W. Dong ${ }^{2}$, Z. G. Zhang ${ }^{2}$, F. L. Hua ${ }^{2}$, L. Zhou ${ }^{2}$, N. Cornilleau-Wehrlin ${ }^{4}$, B. de Laporte $^{4}$, M. Parrot ${ }^{5}$, H. Alleyne ${ }^{6}$, \\ K. Yearby ${ }^{6}$, O. Santolík ${ }^{7,8}$, and C. Mazelle ${ }^{9}$ \\ ${ }^{1}$ Key Laboratory of Space Weather, Center for Space Science and Applied Research, Chinese Academy of Sciences, Beijing, \\ 100080, China \\ ${ }^{2}$ DSP Payload Subsystem, Center for Space Science and Applied Research, Beijing, China \\ ${ }^{3}$ Graduate School of the Chinese Academy of Sciences, Beijing 100039, China \\ ${ }^{4}$ Center d'Environnement Terrestre et Planetaire, Velizy, France \\ ${ }^{5}$ Laboratory de Physique et Chimie de l'Environnement, Orleans, France \\ ${ }^{6}$ University of Sheffield, Automatic Control/System Engineering, Sheffield, UK \\ ${ }^{7}$ Faculty of Mathmatics and Physics, Charles University, Prague, Czech Republic \\ ${ }^{8}$ Institute of Atmospheric Physics, ASCR, Prague, Czech Republic \\ ${ }^{9}$ Centre d'Etude Spatiale des Rayonnements, 31028, Toulouse, France
}

Received: 17 February 2005 - Revised: 9 June 2005 - Accepted: 20 July 2005 - Published: 8 November 2005

Part of Special Issue "Double Star - First Results"

\begin{abstract}
LFEW is a low frequency electromagnetic wave detector mounted on TC-2, which can measure the magnetic fluctuation of low frequency electromagnetic waves. The frequency range is $8 \mathrm{~Hz}$ to $10 \mathrm{kHz}$. LFEW comprises a boommounted, three-axis search coil magnetometer, a preamplifier and an electronics box that houses a Digital Spectrum Analyzer. LFEW was calibrated at Chambon-la-Forêt in France. The ground calibration results show that the performance of LFEW is similar to that of STAFF on TC-1. The first results of LFEW show that it works normally on board, and that the AC magnetic interference of the satellite platform is very small. In the plasmasphere, LFEW observed the ion cyclotron waves. During the geomagnetic storm on 8 November 2004, LFEW observed a wave burst associated with the oxygen ion cyclotron waves. This observation shows that during geomagnetic storms, the oxygen ions are very active in the inner magnetosphere. Outside the plasmasphere, LFEW observed the chorus on 3 November 2004. LFEW also observed the plasmaspheric hiss and mid-latitude hiss both in the Southern Hemisphere and Northern Hemisphere on 8 November 2004. The hiss in the Southern Hemisphere may be the reflected waves of the hiss in the Northern Hemisphere.
\end{abstract}

Keywords. Magnetospheric physics (Plasma waves and instabilities; Instruments and techniques) - Space plasma physics (Instruments and techniques)

Correspondence to: J. B. Cao

(jbcao@center.cssar.ac.cn)

\section{Introduction}

Since the plasma in the magnetosphere is collisionless, the plasma wave, as a media of collective interaction, is very important in the magnetospheric plasma dynamic process. Waves can transform the energy from one region to another region in space. From a theoretical point of view, there are two kinds of waves in a collisionless plasma: electrostatic waves and electromagnetic waves. However, absolutely pure electrostatic waves are hardly observed in space. The electromagnetic waves have both oscillating electric and magnetic field components. Various electromagnetic waves in the magnetosphere are observed, whose frequencies can range from $10^{-3} \mathrm{~Hz}$ to $10^{9} \mathrm{~Hz}$. Since the satellite itself generates magnetic fields, field sensors are always mounted on booms that extend outside the satellite.

LFEW is the first low frequency electromagnetic wave detector manufactured in China, which is designed to measure low frequency electromagnetic waves in the frequency range of $8 \mathrm{~Hz}-10 \mathrm{kHz}$. The Center for Space Science and Applied Research (CSSAR) of the Chinese Academy of Sciences is responsible for the design and manufacture of LFEW. The Center d'Environnement Terrestre et Planetaire (CETP) in France helped CSSAR to calibrate LFEW.

TC-2 is the polar satellite of DSP, with an apogee of $4 R_{E}$ and a perigee of $500 \mathrm{~km}$. During the mission, TC-2 crosses many important space regions, such as the plasmasphere, radiation belt, auroral zone, cusp and polar cap. In these regions, there exists an abundance of wave activities, which provide the only effective coupling between particles. These 


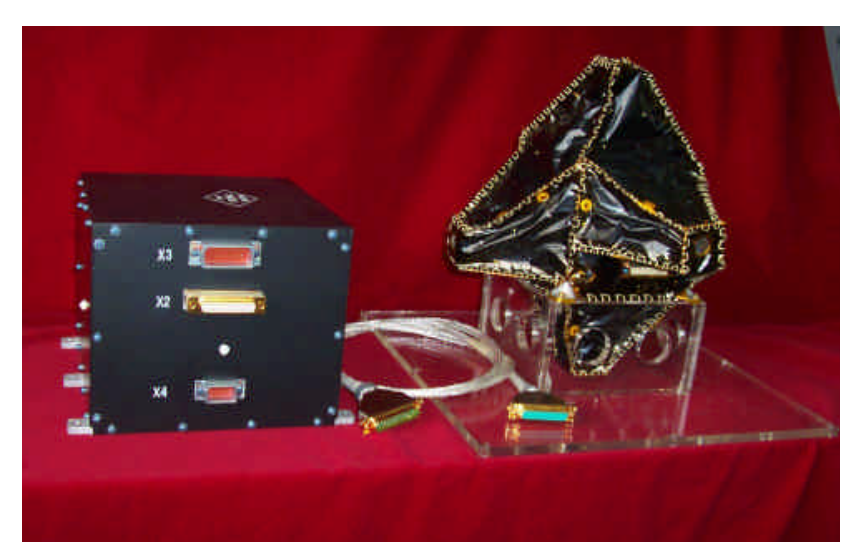

Fig. 1. The picture of the search coil and the electronic box of LFEW/TC-2.

waves have a close relation with solar wind conditions, geomagnetic storms and substorms.

The primary scientific objectives are the following:

- To study the generation mechanism and propagation characteristics of low frequency electromagnetic waves at the plasmapause, and the acceleration, diffusion and precipitation processes of the particles.

- To study the instabilities and generation processes of low frequency electromagnetic waves (e.g. ion cyclotron wave) in the auroral and cusp regions, and their accelerating effects on the upflowing ions $\left(\mathrm{H}^{+}, \mathrm{O}^{+}\right.$and $\left.\mathrm{He}^{+}\right)$.

- To study the generation mechanism of low frequency electromagnetic waves (including magnetic pulsations and Alfvén waves) in the plasma sheet and the plasma sheet boundary layer during magnetospheric substorms and magnetic storms and their relationship with magnetospheric substorms, the heating, acceleration and diffusion processes of ionospheric upflowing ions and plasma sheet thermal ions that interact with these waves.

- To study the plasma instabilities at the dayside magnetopause boundary layer, the generation mechanism, frequency spectrum and propagation characteristics of low frequency electromagnetic waves and magnetic pulsations, and their effects on the transfer of solar wind energy into the magnetosphere.

\section{Instrument description and commissioning results}

The LFEW instrument comprises a boom-mounted threeaxis search coil magnetometer, a preamplifier and an electronics box that houses a digital Spectrum Analyzer.

The instrument characteristics and measured parameters are as follows:
a) Mass: $3.6 \mathrm{~kg}$
b) Power: $5 \mathrm{~W}$
c) Measurement range: $8 \mathrm{~Hz}-10 \mathrm{kHz}$
d) Scientific telemetry rate: $3 \mathrm{kbit} / \mathrm{s}$
e) Size: Sensor $\phi 25 \times 240 \times 300 \mathrm{~mm}^{3}$, Electronic unit $150 \times 180 \times 200 \mathrm{~mm}^{3}$.

Figure 1 shows the search coil and the electronic box of LFEW. The search coil consists of three mutually orthogonal sensors that are mounted on the end of a rigid boom that is $4.0 \mathrm{~m}$ away from the spacecraft center. Two sensors $\left(B_{y}\right.$ and $B_{z}$ of LFEW) lie in the spin plane and the third $\left(B_{x}\right)$ is parallel to the spin axis. The angles between $B_{y}\left(B_{z}\right)$ and the boom is $45^{\circ}$ with an accuracy of $\pm 2^{\circ}$. The frequency response of the sensor is flattened in the frequency range 8$10000 \mathrm{~Hz}$ by a secondary wind used to introduce flux feedback.

There are three preamplifiers located in the electronic unit inside the satellite. The dynamic range of the preamplifiers is $100 \mathrm{~dB}$. The output signals of the preamplifiers are sent to the spectrum analyzer, which then calculates the power spectra density of the three components. The phase differences between the three components are also downlinked. The frequency range of $8 \mathrm{~Hz}-10 \mathrm{kHz}$ is divided into three subbands:

(1) Low frequency band: $10-100 \mathrm{~Hz}$

(2) Middle frequency band: $100-1000 \mathrm{~Hz}$

(3) High frequency band: $1000-10000 \mathrm{~Hz}$.

There are 96 spectrum lines that are distributed over the three frequency bands (32 spectrum lines for each frequency band, some lines overlapped). The three frequency bands each have their own sampling rates:

(1) Low frequency band: $400 \mathrm{~Hz}$

(2) Middle frequency band: $4 \mathrm{kHz}$

(3) High frequency band: $40 \mathrm{kHz}$.

For each of the three bands, there are three separate automatic gain controlled (AGC) amplifiers (for $B_{x}, B_{y}, B_{z}$ respectively) and the gain of these AGC amplifiers has the role of a multiplying factor in the determination of the absolute measurement.

The digital processing of the output signals is in three distinct steps:

(1) De-spin of the spin-plane sensor outputs;

(2) Determination of the complex Fourier coefficients;

(3) Determination of the phase difference between the three components.

The de-spinning operation is necessary since the instrument measurement time interval is not short compared with the satellite spin period $(4 \mathrm{~s})$. Then the treatment of data on the ground will be able to transform the data from the satellite coordinate in to the GSE coordinates.

Since LFEW is the first Chinese low frequency electromagnetic wave detector, we made the design as simple as possible. Therefore, LFEW has only one operation mode and no in-flight calibration. 


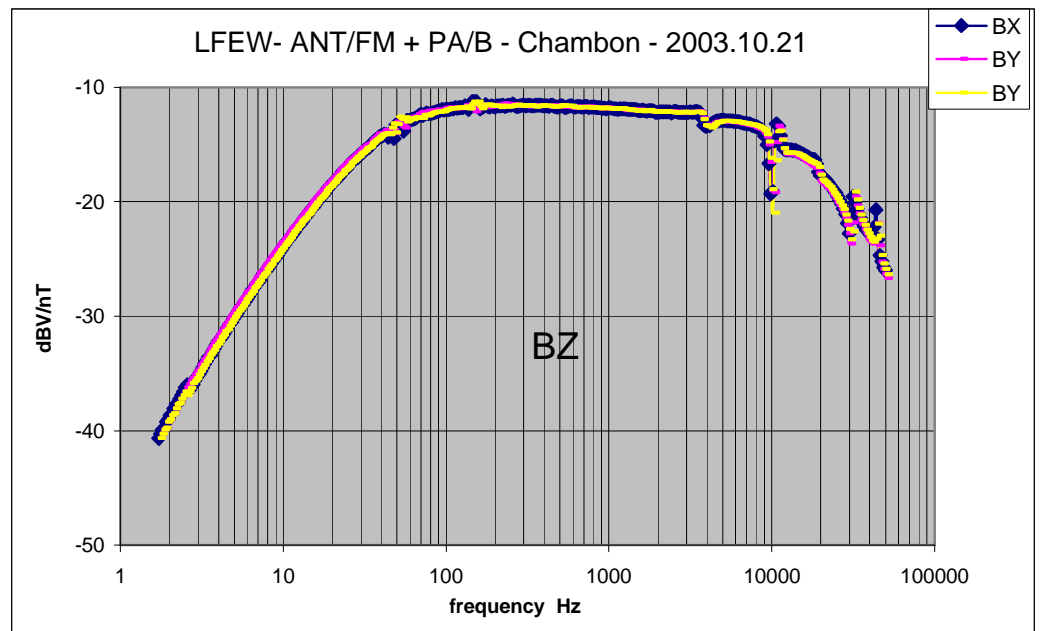

Fig. 2. The transfer functions of three axis search coils of LFEW/TC-2.

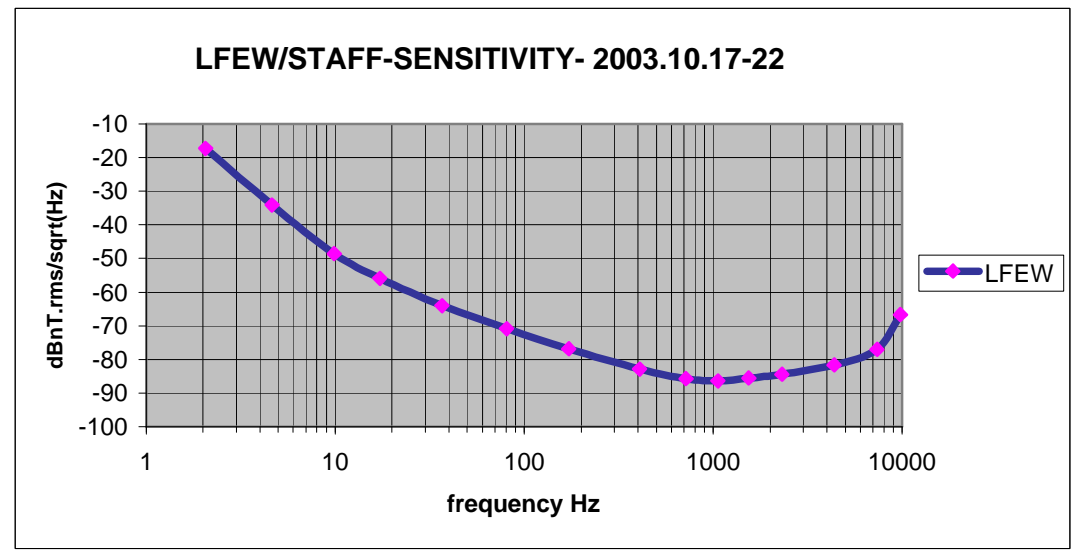

Fig. 3. The sensitivity measured in Chambon de Forêt of LFEW/TC-2.

From ground measurements, the sensitivity of the three mutually orthogonal sensors is $3.0 \times 10^{-3} \mathrm{nT} \mathrm{Hz}^{-1 / 2}$ at $10 \mathrm{~Hz}, 2.5 \times 10^{-4} \mathrm{nT} \mathrm{Hz}^{-1 / 2}$ at $100 \mathrm{~Hz}, 5.6 \times 10^{-5} \mathrm{nT} \mathrm{Hz}^{-1 / 2}$ at $1 \mathrm{kHz}$ and $5.0 \times 10^{-4} \mathrm{nT} \mathrm{Hz}^{-1 / 2}$ at $10 \mathrm{kHz}$ The similarities of the search coils for the three axes are good. The dynamic range of the associated preamplifiers is about $100 \mathrm{~dB}$.

In October 2003, LFEW was calibrated at Chambon-laForêt, the same site used to calibrate the STAFF instrument of Cluster. Figures 2 and 3 show the transfer function and sensitivity of the search coils.

It can be seen that the performances of the three axes are almost the same. Generally, there will be less noise in the space than on the ground. Thus, the in-flight sensitivity is better than on the ground.

\section{First results of LFEW of TC-2}

We analyzed the data of LFEW and found many interesting wave activities. Some preliminary results are discussed below. More detailed studies of the physical process need to be done in the near future.

\subsection{Ion cyclotron waves}

Almost every time when TC- 2 crossed the cusp in the Southern Hemisphere, waves with frequencies below the proton cyclotron frequency $\Omega_{p}$ were observed by LFEW.

Figure 4 shows the ion cyclotron waves observed by LFEW on 16 September 2004, which lasted from 21:17 to 21:39 UT. The blue line in Fig. 4 indicates the local proton cyclotron frequency on the satellite path. The satellite position at $21: 31$ is: $\boldsymbol{R}=(0.38,0.14,1.04) R_{E}$ in SM coordinates, MLT $=13.37$, MLAT $=-68.6^{\circ}$ and $\mathrm{IL}=72.1^{\circ}$. The waves existed both in the plasmasphere and in the cusp. At the entry of the cusp, the waves are relatively weak. Deep in the cusp, 


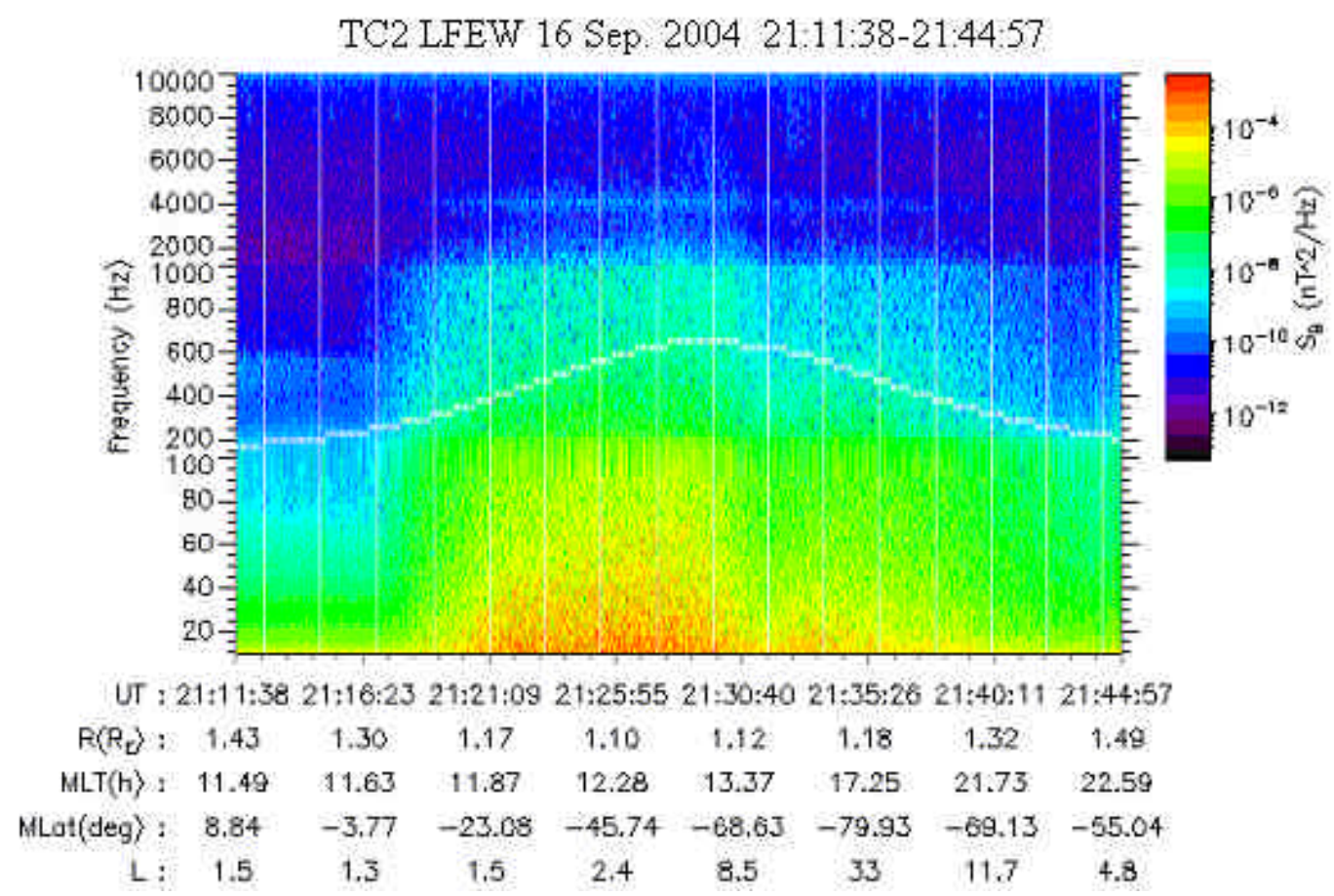

Fig. 4. Ion cyclotron waves observed by LFEW on 16 September 2004.

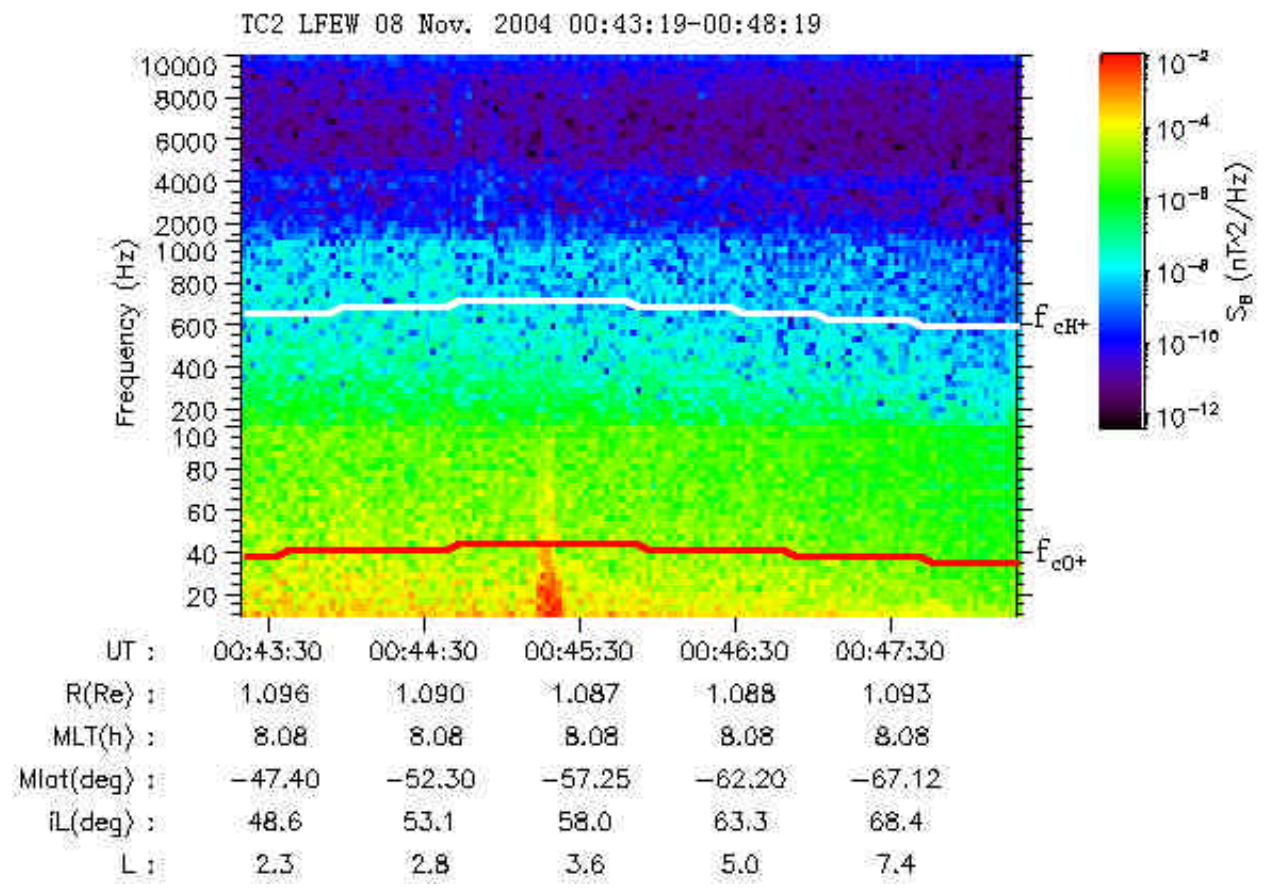

Fig. 5. The time-frequency spectrum observed by LFEW at 00:43:15-00:48:15 UT on 8 November 2004.

the waves become stronger than at the entry. The profile of the wave frequency spectrum seems to have a close relation with the proton cyclotron frequency.
Electromagnetic ion cyclotron waves were detected by many satellites in the plasmasphere (Kintner and Gurnett, 1977; Sonwalker, 1995). Their frequencies generally lie near the ion cyclotron frequencies. Generally, these ion cyclotron waves are excited by precipitating ring current ions 


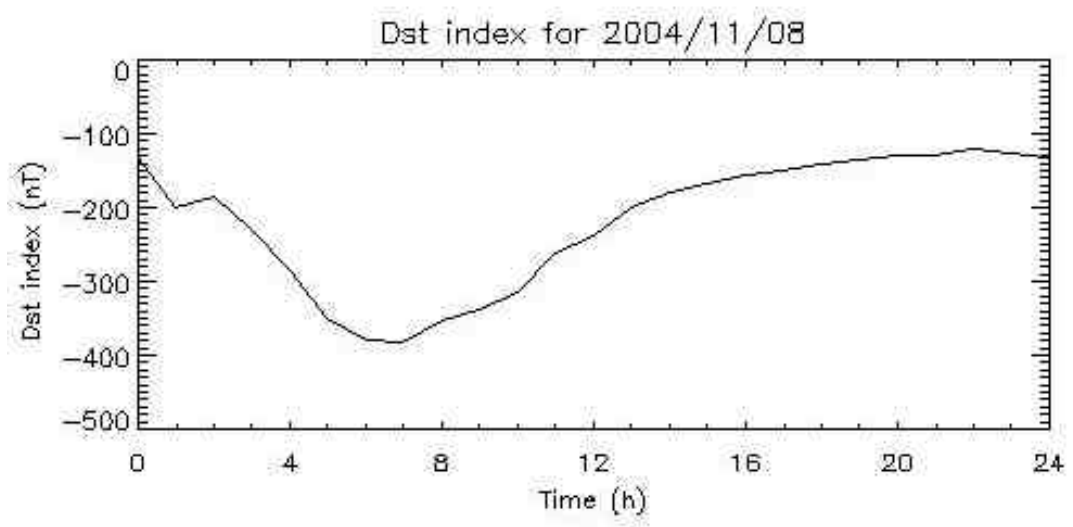

Fig. 6. $D_{s t}$ index on 8 November 2004.

(Sonwalker, 1995). Thus, the ion cyclotron waves between 21:17 and 21:30 UT may be generated by ring current ions.

Pfaff et al. (1998) have identified similar ULF-VLF $(<$ few $\mathrm{Hz}$ ) waves in the cusp using measurements from the Polar electric and magnetic field experiments, and have tentatively identified them as Alfv'en waves. D'Angelo et al. (1974) reported observations from OGO-5 in which ULF magnetic fluctuations were detected at the polar cusp boundaries and were probably due to the Kevin-Helmholtz instability. Gurnett and Frank (1978) reported the presence of a band of ULF-ELF magnetic noise extending from a few Hertz to several hundred Hertz at almost every cusp pass, using Hawkeye I data. They stated that this noise could be used as a reliable indicator of the polar cusp region.

Since the part of the waves in the cusp (from 21:32 to $21: 36)$ is just below the proton cyclotron frequency, it is likely that they are the proton cyclotron waves. However, a more certain conclusion can only be drawn when we know the wave polarization.

\subsection{Wave bursts during geomagnetic storms}

During geomagnetic storms (particularly strong geomagnetic storms), LFEW often observed low frequency wave bursts whose duration was only around $10 \mathrm{~s}$. The data analysis shows that the stronger the geomagnetic storm, the larger the wave burst amplitude. For example, from 00:45:13 to 00:45:24 on 8 November, LFEW observed a wave burst when the satellite was at the position MLT=8.08, MLAT $=-56$. and $\mathrm{L}=3.4$ (see Fig. 5). The proton cyclotron frequency and oxygen cyclotron frequency are indicated by white a line and a red line.

On 8 November 2004, there is a strong geomagnetic storm. The main phase of geomagnetic storm begins at 21:30:00 on 7 November. Figure 6 shows the $D_{s t}$ index on 8 November 2004. Shawhan (1979) mentioned that OGO-5 often observed wave bursts in the plasmasphere and cusp during geomagnetic storms. The waves associated with cyclotron frequencies of heavier $\mathrm{He}^{+}$and $\mathrm{O}^{+}$were detected by many satellites (Mauk et al., 1981; Roux et al., 1982; Gurnett and
Inan, 1988). For example, an event of ion cyclotron waves that was associated with oxygen ion cyclotron frequency was detected inside the plasmasphere by the DE 1 satellite (Gurnett and Inan, 1988). Therefore, it is likely that the wave burst at 00:45:13 is related to the ring current oxygen ion of the storm time.

\subsection{Whistler-mode chorus observations}

Whistler-mode chorus is an electromagnetic wave emission occurring in the Earth's magnetosphere. The generation of these wave packets is not yet well understood. It is most often accepted that chorus is generated by a nonlinear process based on the electron cyclotron resonance of whistlermode waves with energetic electrons (Nunn et al., 1997; Trakhtengerts, 1999; Kennel and Petschek, 1966), taking place close to the geomagnetic equatorial plane (Burton and Holzer, 1974; LeDocq et al., 1998; Parrot et al., 2003; Santolík et al., 2004, 2005). The chorus frequency is closely related to the equatorial electron gyrofrequency.

LFEW often observed whistler mode chorus outside the plasmasphere, which lasted from several hundred $\mathrm{Hz}$ to several kHz. For example, from 08:37.30 to $08: 42: 30$ on 3 November 2004, LFEW observed chorus outside the plasmasphere (see Fig. 7). This wave activity approximately has two frequency bands: $\sim 200 \mathrm{~Hz}-600 \mathrm{~Hz}$ and $800 \mathrm{~Hz}-1 \mathrm{kHz}$. The two bands are separated, since there is almost no wave activity between them. Like the chorus in Fig. 2 of Meredith et al. (2004), the waves of lower frequency band lasted longer than the waves of the higher frequency band.

\subsection{Plasmaspheric hiss and mid-latitude hiss}

Plasmaspheric hiss is a broad-band, structureless, extremely low frequency (ELF) electromagnetic emission, which occurs in the frequency range from a few hundred hertz to several $\mathrm{kHz}$. This natural whistler mode emission is characteristically confined to higher-density regions associated with the Earth's plasmasphere (Dunckel and Helliwell, 1969; Russell et al., 1969; Thorne et al., 1973) or detached plasma regions 
TC2 LFEW 03 Nov. 2004 08:28:27-08:43:26

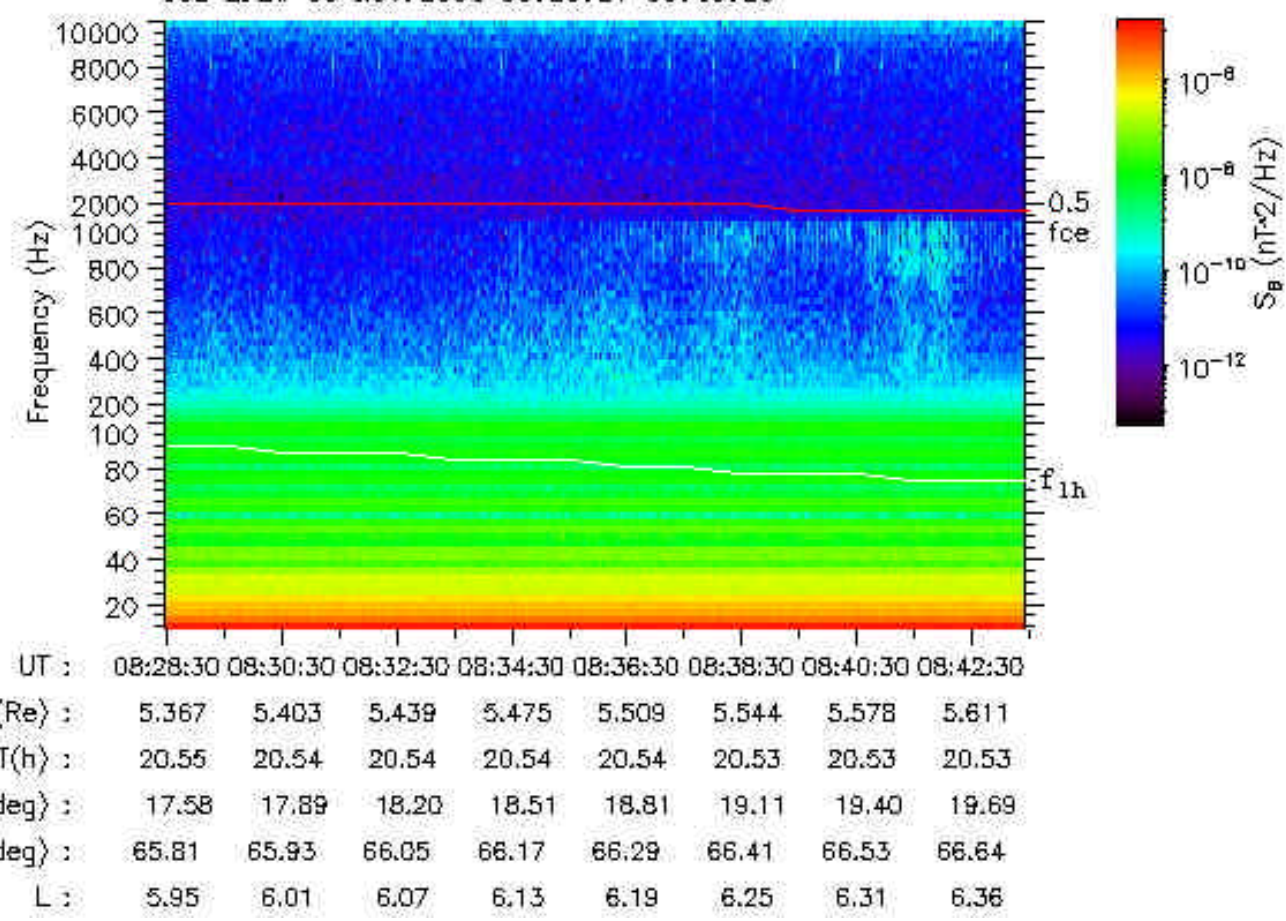

Fig. 7. The time frequency spectrum observed by LFEW at 08:28:30-08:43:30 UT on 8 November 2004.

TC2 LFEW 08 Nov. 2004 11:42:51-11:57:49

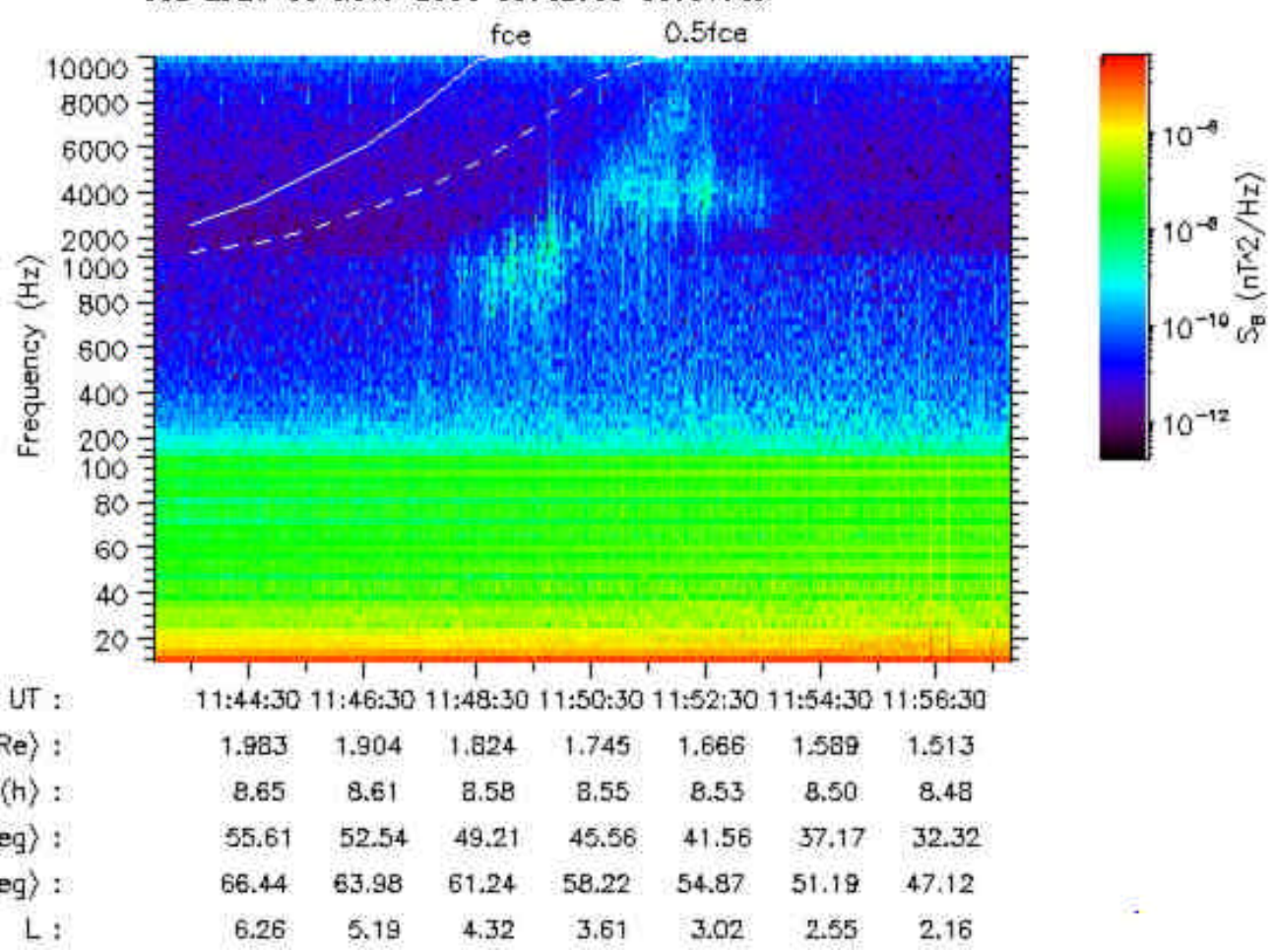

Fig. 8. Plasmaspheric hiss and mid-latitude hiss in the Northern Hemisphere observed by LFEW on 8 November 2004. 


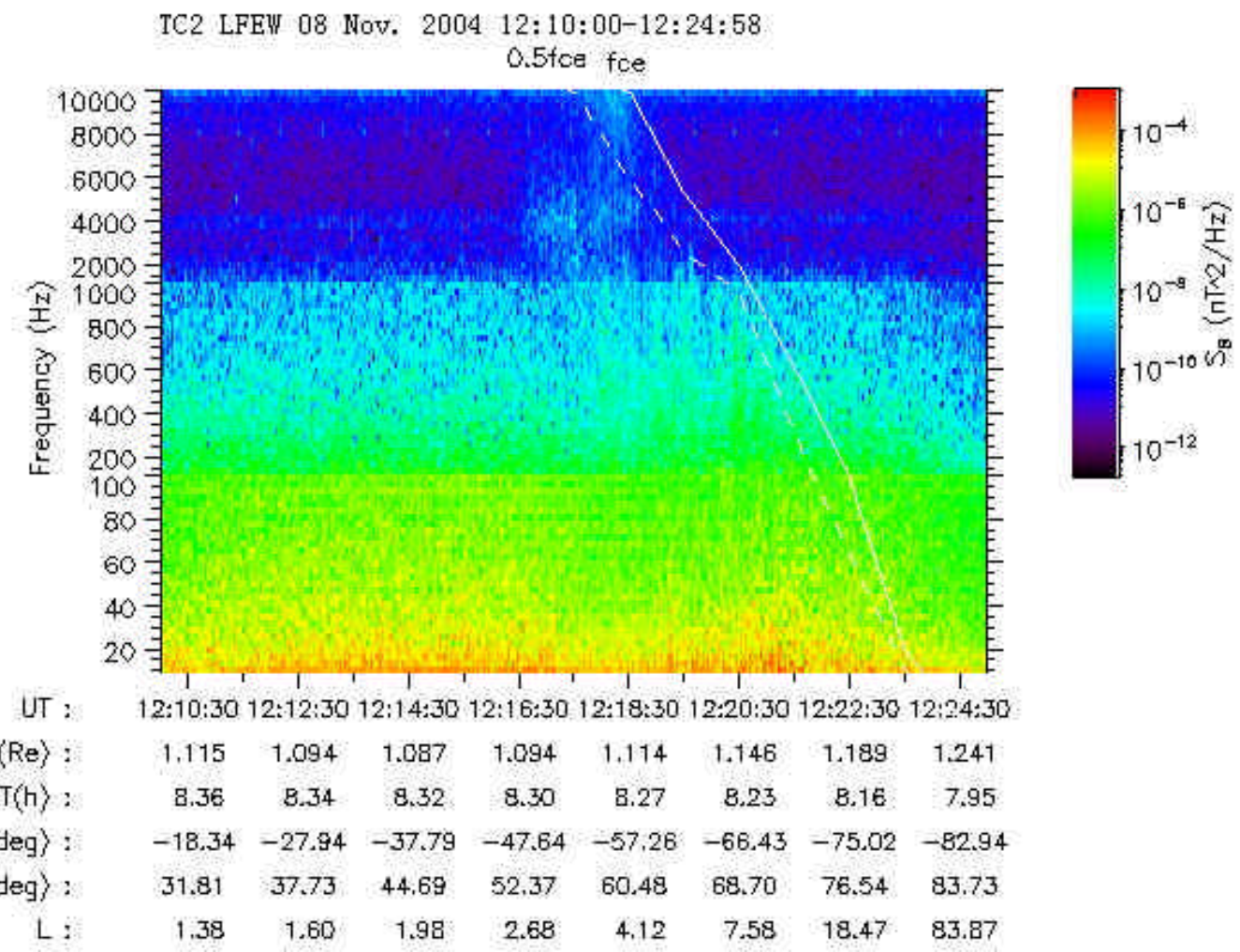

Fig. 9. Plasmaspheric hiss and mid-latitude hiss in the Southern Hemisphere observed by LFEW on 8 November 2004.

(Cornilleau-Wehrlin et al., 1978; Parrot and Lefeuvre, 1986). Plasmaspheric hiss can persist during relatively quiet conditions, but the emission intensifies during magnetic storms or substorms (Smith et al., 1974; Thorne et al., 1974, 1977). Wave intensification has been associated with the injection of plasma sheet electrons into the inner magnetosphere during substorms (Thorne and Barfield, 1976; Solomon et al., 1988; Cornilleau-Wehrlin et al., 1993).

In addition, the mid-latitude hiss between $\sim 2$ to $10 \mathrm{kHz}$ is often observed from the equator to subauroral latitudes. The maximum of their occurrence corresponded to the middle latitudes $\left(55-65^{\circ}\right)$ which are connected with the plasmapause projection (Hayakawa et al., 1975a, b, 1977, 1986, 1988; Dronov et al., 1985; Kleimenova, 1985).

The term "Plasmaspheric hiss" refers to hiss-type ELF emissions observed mostly inside the plasmasphere. The main energy of these emissions is concentrated in the frequency range $100 \mathrm{~Hz}-1 \mathrm{kHz}$, although their upper frequency limit could extend to a few kilohertz (Hayakawa and Sazhin, 1992), It seems possible that the high frequency part of the plasmaspheric hiss spectrum could sometimes result from the influence of mid-latitude hiss (Hayakawa and Sazhin, 1992).

When TC- 2 crossed the plasmasphere, LFEW often observed waves with frequencies from $\sim 300 \mathrm{~Hz}$ to several $\mathrm{kHz}$, which is between the local lower hybrid frequency and the equatorial electron cyclotron frequency. These waves are observed most often during magnetic quiet times and substorms.

Figure 8 gives an example of such waves on 8 November 2004. The wave activity lasted from $11: 47: 28$ to $11: 50: 18$ and 11:50:29 to 11:53:40 UT. The solid line and the dashed line in Fig. 8 indicated the equatorial gyrofrequency $\mathrm{f}_{c e}$ and half equatorial gyrofrequency $0.5 \mathrm{f}_{c e}$. The frequencies of the waves at $11: 47: 28$ to $11: 50: 18$ range from $\sim 300 \mathrm{~Hz}$ to 2.5 $\mathrm{kHz}$. The frequencies of the waves at 11:50:29 to 11:53:40 range from $\sim 2 \mathrm{kHz}$ to $8 \mathrm{kHz}$. Both instances of hiss occurred in the day sector.

Plasmaspheric hiss is stronger in the daytime sector compared to the midnight-to-dawn sector, and generally peaks at high $\left(>40^{\circ}\right)$ latitudes; The mid-latitude hiss between $\sim 2$ $10 \mathrm{kHz}$ is often observed from the equator to subauroral latitudes, at all local times (Sonwalker, 1995). Thus, it is very likely that the lower frequency waves are plasmaspheric hiss and the higher frequency waves are mid-latitude hiss.

Mid-latitude hiss emissions are most likely to be generated in the equatorial magnetosphere where the energy of electrons is transferred to wave energy via the electron cyclotron instability. Some quantitative characteristics of these emissions are explained in terms of a quasilinear model of this instability. Plasmaspheric hiss is closely related to the 
same electron cyclotron instability, although the contribution of other mechanisms cannot be excluded (Hayakawa and Sazhin, 1992; Masson et al., 2004). Thus, sometimes it is very difficult to distinguish between plasmaspheric hiss and mid-latitude hiss. As mentioned in Sect. 3.2, a large geomagnetic storm comprising several substorms occurred on 8 November 2004. Therefore, the plasmaspheric hiss and mid-latitude hiss on 8 November were likely generated by substorm injected electrons.

Figure 9 shows another example of plasmaspheric hiss and mid-latitude hiss on 8 November 2004, which is similar to the hiss in Fig. 8. The interesting point of Fig. 9 is that the plasmaspheric hiss and mid-latitude hiss about Fig. 9 are almost exactly on the magnetic conjugate points of the hiss in Fig. 8.

Hayakawa and Sazhin (1992) pointed out that both midlatitude and plasmaspheric hiss are generated in the equatorial magnetosphere and increase their wave normal angle when propagating away from the magnetic equator, unless there are cross-field gradients in electron density (which can occur, for example, in the vicinity of the plasmapause). When the wave frequency becomes equal to the local lower hybrid frequency, the waves are reflected back to the magnetic equator and thus become trapped within it. Therefore, it can be inferred that the hiss at 12:16:50-12:18:50 represents reflected waves of the hiss at 11:47:28-11:53:40.

\section{Conclusions}

This paper presents briefly the scientific objectives and characteristics of LEFW, and some of the preliminary results of LFEW. More in-depth work is needed to understand the physical process behind these waves.

The first results of LFEW show that it works normally on board, and that the AC magnetic interference of the satellite platform is very small. LFEW has observed various magnetospheric waves. For example, in the plasmasphere, LFEW observed the ion cyclotron waves. During the geomagnetic storm on 8 November 2004, LFEW observed a wave burst associated with the oxygen ion cyclotron waves. This observation shows that during geomagnetic storms, the oxygen ions are very active in the inner magnetosphere. Outside the plasmasphere, LFEW observed the chorus on 3 November 2004. Like the chorus in Fig. 2 of Meredith et al. (2004), the chorus of the lower frequency band lasted longer than the chorus of the higher frequency band. LFEW also observed the plasmaspheric hiss and mid-latitude hiss both in the Southern Hemisphere and Northern Hemisphere on 8 November 2004. The hiss in the Southern Hemisphere may be the reflected waves of the hiss in the Northern Hemisphere.

LFEW is the first Chinese low frequency electromagnetic wave detector. The design principle was to make LFEW as simple as possible so that LFEW coul work reliably. So we removed some functions from STAFF of TC-1. In a future mission, we hope to update the design of LFEW based on the experience obtained in the DSP mission. For example, we hope to add in-flight calibration, a burst mode and waveform output.

Acknowledgements. This work is supported by NSFC Grant 40390151 and 40390153. We are very grateful to CETP and LPCE in France, and University of Sheffield in UK for their kind help in the design and calibration of LFEW.

Topical Editor T. Pulkkinen thanks a referee for his/her help in evaluating this paper.

\section{References}

Burton, R. K. and Holzer, R. E.: The origin and propagation of chorus in the outer magnetosphere, J. Geophys. Res., 79, 10141023, 1974.

Chaston, C. C., Ergun, R. E., Delory, G. T., Peria, W., Temerin, M., Cattell, C., Strangeway, R., McFadden, J. P., Carlson, C. W., Elphic, R. C., Klumpar, D. M., Peterson, W. K., Moebius, E., and Pfaff, R.: Characteristics of electromagnetic proton cyclotron waves along auroral field lines observed by FAST in regions of upward current, Geophys. Res. Lett., 25, 2057-2060, 1998.

Cornilleau-Wehrlin, N., Gendrin, R., Lefeuvre, F., Parrot, M., Grard, R., Jones, D., Bahnsen, A., Ungstrup, E., and Gibbons, W.: VLF electromagnetic waves observed onboard GEOS-1, Space Sci. Rev., 22, 371-382, 1978.

Cornilleau-Wehrlin, N., Solomon, J., Korth, A., and Kremser, G.: Generation mechanism of plasmaspheric ELF/VLF hiss: A statistical study from GEOS 1 data, J. Geophys. Res., 98, 21, 471479, 1993.

D’Angelo, N., Bahnsen, A., and Rosenbauer, H.: Wave and Particle Measurements at the Polar Cusp, J. Geophys. Res., 79, 31293134, 1974.

Dronov, A. V., Fedyakina, N. I., and Khorosheva, O. V.: The interrelationship of subauroral bursts of VLF hiss, precipitating electrons and the plasmapause (English translation), Geomagn. Aeronomy, 25, 87-92, 1985.

Dunckel, N. and Helliwell, R. A.: Whistler-mode emissions on the OGO-1 satellite, J. Geophys. Res., 74, 6371-6385, 1969.

Gurnett, D. A. andFrank, L. A.: Plasma waves in the polar cusp: Observations freom Hawkeyel, J.Geophys.Res., 83, 14471462,1978.

Gurnett, D. A. and Inan, U. S.: Plasma wave observations with the Dynamics Explorer 1 spacecraft, Rev. Geophys., 26, 285-316, 1988.

Hayakawa, M., Tanaka, Y., and Ohtsu, J.: The morphologies of low-latitude and auroral VLF "hiss", J. Atmos. Terr. Phys., 37, 517-529, 1975a.

Hayakawa, M., Tanaka, Y., and Ohtsu, J.: Satellite and ground observations of magnetospheric VLF hiss associated with the severe magnetic storm on May 25-27, 1967, J. Geophys. Res., 80, 86-92, 1975b.

Hayakawa, M. and Tanaka, Y.: ELF emissions observed at Moshiri, Nature, 270, 703-705, 1977.

Hayakawa, M., Tanaka, Y., Sazhin, S. S., Okada, T., and Kurita, K.: Characteristics of dawnside midlatitude VLF emissions associated with substorms as deduced from the two-stationed direction finding measurement, Planet. Space Sci., 34, 225-243, 1986.

Hayakawa, M., Tanaka, Y., Sazhin, S. S., Tixier, M., and Okada, T., Substorm-associated VLF emissions with frequency drift ob- 
served in the premidnight sector, J. Geophys. Res. 93, 56855700, 1988.

Hayakawa, M. and Sazhin, S. S.: Mid-latitude and plasmaspheric hiss: a review, Planet. Space Sci., 40, 1325-1338, 1992.

Kennel, C. F. and Petschek, H. E.: Limit on stable trapped particle fluxes, J. Geophys. Res., 71, 1-28, 1966.

Kintner Jr., P. M. and Gurnett, D. A.: Observation of ion cyclotron waves within the plasmasphere, J. Geophys. Res., 82, 23142318, 1977.

Kleimenova, N. G.: Subauroral VLF and ELF radiation and the main ionospheric trough (English translation), Geomagn. Aeronomy, 25, 220-232, 1985.

LeDocq, M. J., Gurnett, D. A., and Hospodarsky, G. B.: Chorus source locations from VLF Poynting flux measurements with the Polar spacecraft, Geophys. Res. Lett., 25, 4063-4066, 1998.

Masson, A., Inan, U. S., Laakso, H., Santolík, O., and Decreau, P.: Cluster observations of mid-latitude hiss near the plasmapause, Ann. Geophys., 22, 2565-2575, 2004,

SRef-ID: 1432-0576/ag/2004-22-2565.

Mauk, B. H., Mcllwain, C. E., and McPherron, R. L.: Helium cyclotron resonance within the Earth's magnetosphere, Geophys. Res. Lett., 8, 103-106, 1981.

Meredith, N. P., Horne, R. B., Thorne, R. M., Summers, D., and Anderson, R. R.: Substorm dependence of plasmaspheric hiss, J. Geophys. Res., 109, A06209, doi:10.1029/2004JA010387, 2004.

Nunn, D., Omura, Y., Matsumoto, H., Nagano, I., and Yagitani, S.: The numerical simulation of VLF chorus and discrete emissions observed on the Geotail satellite using a Vlasov code, J. Geophys. Res., 102, 27 083-27 097, 1997.

Parrot, M. and Lefeuvre, F.: Statistical study of the propagation characteristics of ELF hiss observed on GEOS 1, inside and outside the plasmasphere, Ann. Geophys., 4, 363-384, 1986.

Parrot, M., Santolík, O., Cornilleau-Wehrlin, N., Maksimovic, M., and Harvey, C.: Source location of chorus emissions observed by Cluster, Ann. Geophys., 21, 473-480, 2003,

SRef-ID: 1432-0576/ag/2003-21-473.

Pfaff, R., Hsieh, S. Y., Clemmons, J., Scudder, J., Kletzing, C., et al.: ULF/VLF Electric Field Signatures in the High Altitude Cusp (Abstract), EOS Trans. AGU, 79, S312, 1998.
Roux, A., Perrout, S., Rauch, J. L., DeVilledary, C., Kresmser, G., Knorth, A., and Young, D. T.: Wave particle interactions near $\Omega_{H e}^{+}$onboard GEOS 1 and 2: generation of ion cyclotron waves and heating of $\mathrm{He}^{+}$ions, J. Geophys. Res., 87, 8174-8190, 1982.

Russell, C. T., Holzer, R. E., and Smith, E. J.: Observations of ELF noise in the magnetosphere, 1 . Spatial extent and frequency of occurrence, J. Geophys. Res., 74, 755-777, 1969.

Santolík, O., Gurnett, D. A., and Pickett, J. S.: Multipoint investigation of the source region of storm-time chorus, Ann. Geophys., 22, 2555-2563, 2004,

SRef-ID: 1432-0576/ag/2004-22-2555.

Santolík, O., Gurnett, D. A., Pickett, J. S., Parrot, M., and Cornilleau-Wehrlin, N.: Central position of the source region of storm-time chorus, Planet. Space Sci., 53, 299-305, 2005.

Shawhan, S. D.: Magnetospheric plasma wave research 1975-1978, Reviews of Geophysics and Space Physics, 17, 705-724, 1979.

Smith, E. J., Frandsen, A. M., Tsurutani, B. T., Thorne, R. M., and Chan, K. W.: Plasmaspheric hiss intensity variations during magnetic storms, J. Geophys. Res., 79, 2507-2510, 1974.

Solomon, J., Cornillieau-Wehrlin, N., Korth, A., and Kremser, G.: An experimental study of ELF/VLF hiss generation in the Earth's magnetosphere, J. Geophys. Res. 93, 1839-1847, 1988.

Sonwalkar, V. S.: Magnetospheric LF-, VLF-, and ELF-Waves, in: Handbook of Atmospheric Electrodynamics, edited by: Volland, H., CRC Press, Inc., 407-462, 1995.

Thorne, R. M., Smith, E. J., Burton, R. K., and Holzer, R. E.: Plasmaspheric hiss, J. Geophys. Res., 78, 1581-1596, 1973.

Thorne, R. M., Smith, E. J., Fiske, K. J., and Church,S. R.: Intensity variation of ELF hiss and chorus driving isolated substorms, Geophys. Res. Lett., 1, 193-201, 1974.

Thorne, R. M. and Barfield, J. N.: Further observational evidence regarding the origin of plasmaspheric hiss, Geophys. Res. Lett., 3, 29-32, 1976.

Thorne, R. M., Church, S. R., Malloy, W. J., and Tsurutani, B. T.: The local time variation of ELF emissions during periods of substorm activity, J. Geophys. Res., 82, 1585-1590, 1977.

Trakhtengerts, V.: A generation mechanism for chorus emission, Ann. Geophys., 17, 95-100, 1999,

SRef-ID: 1432-0576/ag/1999-17-95. 